\title{
Home care in cystic fibrosis patients
}

\author{
W.M.C. van Aalderen*, G.P.M. Mannes**, E.S. Bosma+, \\ R.J. Roorda ${ }^{++}$, H.S.A. Heymans*
}

\begin{abstract}
Home care in cystic fibrosis patients. W.M.C. van Aalderen, G.P.M. Mannes, E.S. Bosma, R.J. Roorda, H.S.A. Heymans. CERS Journals Ltd 1995.

ABSTRACT: Intravenous antibiotics and enteral tube feeding at home for the treatment of pulmonary exacerbations and underweight condition in cystic fibrosis (CF) patients have become tools that are used in many cystic fibrosis centres. The experience with home care programmes from different countries is quite conclusive. If the necessary preparations are made, such as training of staff and patients, and financial support is arranged, home care is easy to put into practice. Optimal patient compliance is also necessary.

Home care is as effective as hospital treatment for selected patients, and less expensive. Experience has increased during many treatment periods in different cystic fibrosis centres, and only a few adverse events have been recorded, indicating that home care is safe. However, the most important gain for cystic fibrosis patients is the reduction of hospital admission time, which means a definite improvement in the quality of life.

Eur Respir J., 1995; 8, 172-175.
\end{abstract}

Depts of *Paediatric Pulmonology and Paediatrics, and **Pulmonology, Beatrix Children's Hospital University Hospital Groningen, The Netherlands. +KITTZ, Institute for Quality and Applied Home Care Innovation, Groningen, The Netherlands. ${ }^{++}$Dept of Paediatric Pulmonology, Hospital "De Weezelanden", Zwolle, The Netherlands.

Correspondence: W.M.C. van Aalderen Dept of Paediatric Pulmonology Beatrix Children's Hospital

University Hospital Groningen Oostersingel 59 9713 EZ Groningen The Netherlands

Keywords: Cystic fibrosis, home care

Received: April 51994

Accepted after revision October 151994
The improved survival in cystic fibrosis $(\mathrm{CF})$ patients is mainly the result of an earlier diagnosis of the disease, and of a better control of pulmonary exacerbations, growth and nutritional status. Recent developments in the therapy of $\mathrm{CF}$ patients, such as lung transplantation, and future developments, such as gene therapy, may further extend survival. Intravenous antibiotic treatment of pulmonary exacerbations, especially in older patients with more advanced pulmonary disease, and hyperalimentation formerly required weeks of hospital admission. Home therapy has been developed by a number of $\mathrm{CF}$ centres and primarily improves the quality of life for patients and their relatives [1].

When CF was first described in the 1930s, few children suffering from the disease survived beyond $5 \mathrm{yrs}$ of age. In recent years, this has been extended to almost 30 yrs of age, and the estimated life expectancy of patients who are born at present is 40 yrs [2, 3]. This increased life expectancy is mainly attributable to improved pulmonary management [2], but also to a better understanding of the nutritional problems [4], better physical training programmes [5], centre care and a multidisciplinary approach $[6,7]$.

The drawback of increased life expectancy is the necessity of intensive therapy, with numerous weeks of hospitalization per year, reducing the quality of life. Frequent hospital admissions are necessary for intravenous antibacterial treatment of pulmonary exacerbations, and for enteral tube or intravenous feeding in case of malnutrition, especially during the end-stage of the disease. For patients, the advantage of receiving this treatment at home is that they can continue to work or attend school.

\section{Home care}

\section{Benefits}

Home therapy has been developed in several CF centres in different countries during the last two decades and has the following obvious advantages: 1) reduction in the number of hospital admission days, and, therefore, improved quality of life; 2) better compliance to treatment by earlier intervention in the course of exacerbations; 3 ) increased independence from the hospital; and 4) reduced risk of cross-infections with Pseudomonas aeruginosa.

The financial benefits depend upon the insurance programmes in the different countries, and the organization of home care. Studies from most countries report financial benefits [8-10].

\section{Disadvantages}

A potential disadvantage is that home care could be experienced as a further therapeutic burden at home. Home care provokes the risk that patients do not have 
the discipline to intensify their chest physiotherapy. Moreover, home treatment has the potential risk of the development of serious allergic reactions to antibiotics. The antibiotics employed at home should have been used during hospital admissions on earlier occasions by all patients. During each home treatment course, the initial doses of antibiotics have to be given in hospital. These safety measures certainly reduce the risk of allergic reactions.

Another risk of home care is that, for convenience sake, dosing schedules of antibiotics are used which do not conform to the pharmacokinetic characteristics of the drug. Monotherapy for instance, has the potential risk of inducing early antibiotic resistance.

\section{Organization of the programme}

Different organizational forms of home care programmes are used. In some hospitals, physicians are involved in every aspect of the programme [10] but, in general, specially trained nurses play a major role in home care $[1,11-15]$. These are extremes of a wide range of possibilities. A home care organization must guarantee year round $24 \mathrm{~h}$ continuity in patient care. The financial consequences of health care have become very important today, and the use of existing organizations to implement programmes, such as Cross Societies involved in community health care, can help to keep expenses down. An existing organization can provide continuity in care, in contrast to a special programme with one or two specially appointed nurses. Moreover, additional nurses will lead to increased costs.

Our CF team started a home care programme in 1991, in collaboration with KITTZ, a Dutch Institute for Quality and Applied Home Care Innovation. The programme was meant to introduce i.v. treatment and enteral tube feeding at home. KITTZ developed from a former Cross Society; its aim is to increase the possibilities for self-support. As part of a wide range of innovative projects, KITTZ has developed new options in home care; resulting in a Home Care Programme. Following implementation of the programme in our hospital, it was transferred to various local hospitals and adjusted to their individual situation and facilities. Our hospital continued the programme and set up a home care co-ordination team for various chronic diseases. In addition to $\mathrm{CF}$, these include chronic obstructive pulmonary diseases, multiple sclerosis, and rheumatoid disorders. A team of nurses, in collaboration with the subdivisions responsible for the various patient groups, performs home care for all these groups. The advantage is that a larger group, which is part of an existing organization, provides continuity, and that further development in home care is guaranteed for a longer period.

Besides physicians and nurses, hospital or local chemists must also participate, and be prepared to deliver the various antibiotic solutions in the application devices within one or two days. Moreover, general practitioners, local physiotherapists and dieticians should be informed that i.v. treatment and/or enteral tube feeding is being administered at home.

\section{Conditions for home care in cystic fibrosis}

Comprehensive planning of all aspects of home care for patients with $\mathrm{CF}$ is essential to minimize medical and emotional risk for patients and their relatives, and to prevent unforeseen financial burdens. Several studies have addressed this subject before starting home care [16]. Aspects that should be standardized are patient selection criteria, information and training before enrolment in the programme, financial arrangements, and equipment and supplies.

\section{Patient selection}

For every patient, and for every treatment course, the pros and cons should be considered. Patients and their relatives should be able to choose between treatment at home or in hospital each time. During home treatment, the hospital must be prepared to admit the patient whenever this is requested.

From a medical point of view, it should be clear that entering a home programme does not mean that the patient can always receive home treatment. The patient's condition must be stable and should not be exposed to extra risks. If patients and relatives are unable to carry out home treatment, it should be discontinued.

\section{Information and training}

Before home treatment is started, the paediatrician or pulmonologist should provide extensive verbal and written information about all aspects of home treatment. This information should include the names and phone numbers available $24 \mathrm{~h}$ a day, or the numbers of teletracers, of the responsible doctors and supportive nursing staff.

After having received and understood the information, patients and relatives should be given the opportunity to practice the necessary skills when the patient is in a stable phase of the disease. We set up a "Skills Laboratory", where patients can practise with the different tools. A log-book with all the necessary instructions is distributed. Patients can use this log-book to record their use of medication, and any minor problems during home treatment. All actions are repeated several times during the hospital admission preceding home treatment.

Before discharge, the doctor responsible should thoroughly verify whether patients or relatives are able to execute all actions. The first day after discharge, patients and relatives are again instructed by one of the nurses of our home care organization.

\section{Financial arrangements}

Intravenous therapy or enteral tube feeding is expensive, and should not be an extra financial burden for $\mathrm{CF}$ families. In most countries, home treatment is only possible with the permission of health insurance companies. Health insurance companies in The Netherlands 
refused to pay for antibiotics which were administered at home and were supplied by the hospital chemist [17]. Fortunately, most of the companies in our country have changed their rules on this subject over the last few years.

\section{Equipment and supplies}

Equipment must be light and easy to handle. In our adult programme we used ordinary i.v. cannulae, or a subcutaneous implanted central venous access port (PortA-Cath, Kabi Pharmacia, Woerden, The Netherlands). For children without a Port-A-Cath, we used flexible silastic lines (Per-Q-Cath 1, 9 Fr, Laprolan, Beuningen, The Netherlands), originally developed for neonates. These lines are inserted approximately $10 \mathrm{~cm}$ into a peripheral vein. In smaller children, they provide the advantage of allowing them to walk about freely, without being bothered by a splint.

In all cases of i.v. treatment, we used the CADD plus pump (Kabi Pharmacia, Woerden, The Netherlands) for continuous infusion of ceftazidime and the Intermate ${ }^{\circledR} 200$ (Baxter, Utrecht, The Netherlands) or the Homepump ${ }^{\circledR}$ (NPBI, Amstelveen, The Netherlands) for intermittent application of aminoglycosides, such as tobramycin. Intermate ${ }^{\circledR}$ and Homepump ${ }^{\circledR}$ are drugfilled balloons (elastomere infusion devices) inflated by the injected solution. They can be connected to the i.v. system, and are emptied as a result of the wall tension of the balloon within approximately half an hour.

\section{Implementation}

The implementation of most programmes has encountered only minor complications. This is mostly due to the fact that patients and their families are wellinformed and well-trained. All CF centres that started an i.v. home programme have reported that the programme is a success with regard to effectiveness, cost benefits, and most of all, with regard to an improvement in the quality of life. Adverse effects are scarce and of minor importance.

\section{Effectiveness}

Some 15 yrs ago, KuzEMKo and co-workers [8, 18] set up a programme of out-patient i.v. treatment, and in 1982 developed it into home management, with the aim of improving quality of life. DonATI et al. [9] demonstrated, in a prospective controlled study, that both i.v. hospital treatment and i.v. home treatment resulted in significant improvement of pulmonary function and arterial oxygen tension $\mathrm{PaO}_{2}$ values. In 1984, WINTER et al. [19] demonstrated that self-administration of i.v. antibiotics reduced hospital stay, and that this therapy was not associated with an increased rate of recurrent infections. MARTINEZ et al. [20] reported an improvement in pulmonary function and body weight in adult patients. More recently, $\mathrm{CF}$ centres from other European countries have found that home treatment is as effective as hospital treatment $[1,14,15,21]$.

In addition, as part of their therapeutic regimen, $\mathrm{CF}$ patients are offered training programmes in order to prevent muscle mass loss and decline in exercise tolerance. Exercise tolerance can be improved in CF patients [22, 23], and, probably more important, can be maintained on an out-patient basis [24].

Nevertheless, despite all these positive study results, it should be realized that these data are potentially biased by the fact that patients treated at home are only a subsample of the entire CF population.

\section{Cost benefits}

With regard to financial costs, the literature is unambiguous. Studies from Sweden [1], the UK [8], The Netherlands [10], France [9], and the USA [25], evaluating this subject from different backgrounds, all indicate that home treatment provides substantial economic savings.

\section{Quality of life}

The social benefits of home treatment are evident, but difficult to quantify. Improvement in the quality of life has been reported in many studies. STRANDVIK et al. [1] reported that $96 \%$ (all except one) of patients preferred this type of treatment. Data from BAKKER et al. [10] and GILBERT et al. [15] agree with this finding.

\section{Adverse events}

Most CF groups have reported few and minor adverse events during home care. Our own experiences from October 1991 to December 1993, with 131 i.v. treatment periods in 20 patients, are in agreement with other findings. At the start of our programme, two patients had a deprogrammed infusion pump, which was replaced by the company. Another patient, who ran out of infusion solution on one occasion, kept his silastic line open with a heparin lock. A more general problem was that the infusion time for the intermittent aminoglycoside application was longer than expected $(+1 \mathrm{~h})$. On three occasions, an adult patient had to return to hospital because of an obstructed i.v. cannula. A 16 year old girl had recurrent obstructed i.v. cannulae and silastic lines, without a demonstrable reason, during a single treatment period of 3 weeks. After implantation of a venous access port, these problems were resolved. STRANDVIK and co-workers [1] reported that one inserted venous cannula could be used for the whole treatment period in $30 \%$ of the courses. Sola et al. [26] investigated complications of 22 implanted access ports in $15 \mathrm{CF}$ patients. The overall complication rate was low. Infectious and mechanical complications were extremely infrequent. However, superior vena cava syndrome or deep venous thrombosis were associated with 3 out of 22 catheters. Sola et al. [26] advised the prescription 
of aspirin. Frequent flushing of the device (once a month) and the use of a heparin lock may also prevent this serious complication.

The strikingly low complication rate at home may be a consequence of a combination of selection and training of patients, and of the proper use of long indwelling lines and implanted venous access devices. The fact that patients take care of, and are responsible for, their own infusion system is another important factor.

In conclusion, the option of $i . v$. antibiotics and enteral tube feeding at home for the treatment of pulmonary exacerbations and malnourishment in $\mathrm{CF}$ patients has become a tool that is used in many CF centres. The results of home care programmes from different countries are conclusive. If the necessary preparations are made, such as training of staff and patients, and financial support is arranged, home care is easy to put into practice. Optimal patient compliance is also necessary. Home care is as effective as hospital treatment for selected patients, and less expensive. Experience has increased during many treatment periods in different $\mathrm{CF}$ centres, but only a few adverse events have been observed, indicating that home care is safe. In addition to all these positive factors, the most important gain for $\mathrm{CF}$ patients is the reduction of hospital admission time, which means a definite improvement in quality of life.

Before the start of home therapy, careful planning of the programme is necessary. A programme should be standardized in such a way that it can be executed in different locations. The use of existing extramural organizations, such as Cross Societies, or a larger home care team taking care of different patient groups gives long-term continuity and keeps expenses low.

\section{References}

1. Strandvik B, Hjelte I, Malmborg AS, Widen B. Home intravenous treatment of patients with cystic fibrosis. Acta Paediatr 1992; 81: 340-344.

2. British Paediatric Working Party on Cystic Fibrosis Cystic Fibrosis in the United Kingdom 1977-1985 an improving picture. Br Med J 1988; 297: 1599-1602.

3. Collée JM, Cobben JM, Ten Kate LP. Survival of cystic fibrosis patients in the Netherlands. Proc. XIth International Cystic Fibrosis Congress, Dublin, Ireland, 1992 TP 104.

4. Shepherd RW, Holt TL, Thomas BJ, Ward LC, Isles A, Francis PJ. Malnutrition in cystic fibrosis: the nature of nutritional deficit and optimal management. Nutr Abst Rev 1984; 54: 1009-1022.

5. Heijerman HGM, Bakker W, Sterk PJ, Dijkman JH. Oxygen-assisted exercise training in adult cystic fibrosis patients with pulmonary limitation to exercise. Intern J Rehab Res 1991; 14: 136-142.

6. Warwick WJ. Prognosis for survival with cystic fibrosis: effect of early diagnosis and cystic fibrosis center care. Acta Paediatr Scand 1982; 301 (suppl.): 27-31.

7. Nielsen OH, Schiøtz PO. Cystic fibrosis in Denmark in the period 1945-1981: evaluation of centralised treatment. Acta Paediatr Scand 1982: 301 (suppl.); 107-119.

8. Kuzemko JA, Williams KJ. Home intravenous treatment of pulmonary infections in cystic fibrosis. In: David TJ, ed. Cystic Fibrosis in Children: Practical and Legal Aspects of Intravenous Antibiotic Administration in the Home. Amsterdam, Excerpta Medica, 1986: pp. 29-32.

9. Donati MA, Guenett G, Auerbach H. Prospective controlled studies of home and hospital therapy of cystic fibrosis pulmonary disease. J Pediatr 1987; 111: 28-33.

10. Bakker W, Vinks AATMM, Mouton JW, Verzijl JG, Heijerman HGM. Continuous intravenous treatment at home of respiratory tract infections with ceftazidime using a portable pump in cystic fibrosis (CF) patients in The Netherlands; a multicentre study. Ned Tijdschr Geneeskd 1993; 137: 2486-2491.

11. Hammond LJ, Caldwell S, Campbell PW. Cystic fibrosis, intravenous antibiotics, and home therapy. $J$ Pediatr Health Care 1991; 5: 24-30.

12. Gill S. Home administration of intravenous antibiotics to children with cystic fibrosis. $B r J$ Nurs 1993; 8: 767-770.

13. Duncan-Skingle F, Bramwell E. Home help. Nurs Times 1992; 88: 34-35.

14. Sardet A, Feigelson J. Mucoviscidose: traitement a domicile. Rev Prat 1990; 27: 1571-1574.

15. Gilbert J, Robinson T, Littlewood JM. Home intravenous antibiotic treatment in cystic fibrosis. Arch Dis Child 1988; 63: 512-517.

16. Ad hoc task force of chronically ill infants and children. Guidelines for homecare of infants, children and adolescents with chronic disease. Pediatrics 1984; 74: 434-436.

17. Dankert-Roelse JE. Discussion (letter to the editor). Chest 1988; 94 (Suppl.): 165.

18. Kuzemko JA. Home treatment of pulmonary infections in cystic fibrosis. Chest 1988; 94 (suppl.): 162-165.

19. Winter RJ, George RJ, Deacock SJ, Shee CD, Geddes DM. Self-administered home intravenous antibiotic therapy in bronchiectasis and adult cystic fibrosis. Lancet 1984; i: 1338-1339.

20. Martinez MA, Votoroubek W, Hoefle K, Lemen RJ. Efficiency of respiratory home care for cystic fibrosis patients. Am Rev Respir Dis 1987; 135: A194.

21. Van Aalderen WMC, Mannes GPM, Van Bommel G, Voorthuis I, Heymans HSA. Continuous home intravenous treatment of respiratory infections in 11 cystic fibrosis patients in the north of The Netherlands. Ned Tijds Geneeskd 1993; 137: 282-286.

22. Orenstein DM, Franklin BA, Doershuk CF, et al. Exercise conditioning and cardiopulmonary fitness in cystic fibrosis. Chest 1982; 80: 392-398.

23. Edlund DM, French RW, Herbst JJ, Ruttenberg HD, Rubling RO, Adams TD. Effects of a swimming program on children with cystic fibrosis. Am J Dis Child 1986; 140: 80-83.

24. De Jong W, Grevink RG, Roorda RJ, Kaptein AA, Van der Schans CP. Effect of a home exercise training program in patients with cystic fibrosis. Chest 1994; 105 : 463-468.

25. Kane RE, Jennison K, Wood C, Herbst JJ. Cost savings and economic considerations using home intravenous antibiotic therapy for cystic fibrosis patients. Pediatr Pulmonol 1988; 4: 84-89.

26. Sola JE, Stone MM, Wise B, Colombani PM. Atypical thrombotic and septic complications of totally implantable venous access devices in patients with cystic fibrosis. Pediatr Pulmonol 1992; 14: 239-242. 